University of Wollongong

Research Online

SMART Infrastructure Facility - Papers

Faculty of Engineering and Information

Sciences

2016

A review of supply network configuration literature and decision support tools

Subodha Dharmapriya

University of Wollongong, ssd889@uowmail.edu.au

Senevi Kiridena

University of Wollongong, skiriden@uow.edu.au

Nagesh Shukla

University of Wollongong, nshukla@uow.edu.au

Follow this and additional works at: https://ro.uow.edu.au/smartpapers

Part of the Engineering Commons, and the Physical Sciences and Mathematics Commons

Research Online is the open access institutional repository for the University of Wollongong. For further information contact the UOW Library: research-pubs@uow.edu.au 


\title{
A review of supply network configuration literature and decision support tools
}

\author{
Abstract \\ Supply chain literature highlights the increasing importance of effective supply network configuration \\ decisions that take in to account such realities as market turbulence and demand volatility, as well as ever \\ expanding global production networks. Supply network configurations decisions that account for these \\ contingencies are expected to meet the evolving needs of customers while delivering better outcomes for \\ all parties involved. This paper presents the findings of a structured review of supply network \\ configuration literature which is synthesized under the two categories, drivers of supply network \\ configuration decisions and the key parameters considered in developing decision support tools. This \\ review also included an evaluation of the tools used for supporting supply network configuration \\ decisions. The paper identifies the areas for future research, as well as the decision support tools \\ required for building supply network capacity to meet the challenges brought about by the changing \\ business environment.

\section{Keywords} \\ tools, network, literature, decision, supply, support, configuration, review \\ Disciplines \\ Engineering | Physical Sciences and Mathematics

\section{Publication Details} \\ Dharmapriya, U. S. S., Kiridena, S. B. \& Shukla, N. (2016). A review of supply network configuration \\ literature and decision support tools. 2016 International Conference on Industrial Engineering and \\ Engineering Management (pp. 149-153). Danvers, United States: IEEE.
}




\title{
A Review of Supply Network Configuration Literature and Decision Support Tools
}

\author{
U. S. S Dharmapriya ${ }^{1}$, S. B. Kiridena ${ }^{1}$, N. Shukla ${ }^{2}$ \\ ${ }^{1}$ School of MMM Engineering, University of Wollongong, Wollongong, Australia \\ ${ }^{2}$ SMART Infrastructure Facility, University of Wollongong, Wollongong, Australia \\ e-mail: *ssd889@uowmail.edu.au; skiriden@uow.edu.au; nshukla@uow.edu.au
}

\begin{abstract}
Supply chain literature highlights the increasing importance of effective supply network configuration decisions that take in to account such realities as market turbulence and demand volatility, as well as ever expanding global production networks. Supply network configurations decisions that account for these contingencies are expected to meet the evolving needs of customers while delivering better outcomes for all parties involved. This paper presents the findings of a structured review of supply network configuration literature which is synthesized under the two categories, drivers of supply network configuration decisions and the key parameters considered in developing decision support tools. This review also included an evaluation of the tools used for supporting supply network configuration decisions. The paper identifies the areas for future research, as well as the decision support tools required for building supply network capacity to meet the challenges brought about by the changing business environment.
\end{abstract}

Keywords - Decision support, supply chain, supply network configuration

\section{INTRODUCTION}

There is wide-ranging consensus that economic wars of the 21 st century are essentially fought based on supply networks, rather than as a collection of high-performing enterprises [1-4]. Customers are increasingly demanding "perfect-orders" at globally competitive prices. A perfect order is interpreted as an order delivered to meet the customer's requested date and time in perfect condition with all required documentation [5][31]. Fulfilling perfect orders requires sustaining "efficient, fast and tailored" supply networks. Against this background, recent literature has highlighted the importance of effective supply network configuration (SNC) decisions that take in to account such realities as market turbulence and demand volatility, and the inherent complexities of the supply networks themselves [4]. Such SNC decisions are expected to build supply network capacity to: deal with the uncertainties induced by demand variations and supply disruptions; respond to changing market needs and customized orders; and adopt new technologies and organizational practices [8] [29-30].

From a traditional network design perspective, SNC involves the integration of product, process and logistics decisions for the purpose of ensuring a swift and even flow of material through the supply chain [6-7]. However, more contemporary interpretations of the term refer to "the instantiation of a generic supply network to specific supply chains" [7: p. 6681]. The latter view recognizes that the real value adding potential of a supply network as a whole lies in the way it is configured. That is, how the various processes and resources are combined to create and deliver a superior "customer value proposition" while taking into account the contingencies driven by evolving product-market profiles, as well as the changes in organizational priorities and the environmental conditions outlined previously. As such, we consider SNC decisions in terms of the alternative arrangements of supply network entities, processes, and resources when there are multiple options available to differentiate them in terms of the key performance metrics such as cost, lead time and fill rate [9-12].

In this paper, we present the results of a structured review of SNC literature undertaken to evaluate the current status of research in this area. The literature review investigated two key issues: (i) to what extent the SNC problem has been explored in the extant literature in addressing the drivers of SNC decisions; and (ii) what decision parameters have been considered in developing decision support (DS) tools. The review consisted of a bibliometric analysis, as well as a content analysis, of 20 SNC articles sourced from four major databases. The results of the bibliometric analysis confirmed that the literature holistically focusing on the SNC problem (i.e. incorporating multiple decisions across the entire supply network) is only beginning to emerge. The content analysis revealed various knowledge gaps in addressing the SNC problem, as well as opportunities for developing advanced DS tools.

\section{REVIEW METHODOLOGY}

We first conducted a title/abstract/keywords query using the search string; "supply chain*" OR "supply network*" AND "configuration" OR "reconfiguration" OR "re-configuration". This search was limited to peerreviewed journal articles in the four databases: Scopus; Web of Science; Business Source Complete and ABI Inform. The number of articles drawn from each database are: Scopus - 890; Web of Science - 518; Business Source Complete - 267; and ABI Inform - 288. We then exported all these articles to the endnote reference manager software and duplicates were removed. The articles were then subjected to sequential screening and reviewing at the three levels of title, abstract and full content. Articles were then screened based on three key criteria: (i) the focus on the configuration problem as to whether it follows the definition adopted by this study; (ii) addressing at least one SNC decision; and (iii) whether the major contribution of the study was a DS tool for 
solving the SNC problem. The application of these three criteria resulted in a total of 20 articles which then underwent a bibliometric and content analyses as follows.

\section{BIBLIOMETRIC ANALYSIS}

The bibliometric analysis focused on identifying three attributes: contribution of individual authors; the number of publications per year; and the number of publications per journal, to appraise the scholarly background of research contributions.

Contributions by author: there were 50 individuals who contributed to the 20 articles reviewed and 7 (out of the 50) authors (as given in Table 1) had contributed to more than one article.

Number of publications per year: there were no articles published prior to 2005 on the topic and the highest number of articles (5) was published in 2005. The number of publications in each year is given in Table 2 .

Number of publications per journal: thirteen out of the 20 articles had been published in four journals: International Journal of Production Research (6); International Journal of Production Economics (3); International Journal of Advanced Manufacturing Technology (2); and European Journal of Operational Research (2). The remaining 7 articles had been published, one each, in 6 journals as shown in Table 3 .

In summary, the bibliometric analysis confirmed that SNC as a research area is yet to be established, despite its increasing significance and practical relevance as reported in more recent literature and a number of industry surveys [1-2][4]. Furthermore, there were no clear trends in the yearly publication statistics to confirm a growing interest in the area.

\section{CONTENT ANALYSIS}

The primary intention of the content analysis was to investigate the current status of DS tools in SNC research with a particular focus on the two perspectives: (i) drivers of supply network configuration (SNC) decisions; and (ii) the decision parameters considered in developing DS tools.

\section{A. Drivers of SNC Decisions}

In light of the SNC definition adopted in this study, key drivers of SNC decisions have been considered in terms of structural, temporal and environmental characteristics. The relevance of those factors to this study stems from the need to: (i) assess the level of the generalization of SNC problem in the extant literature; and (ii) investigate the robustness of the available DS tools. A summary account of the most frequently cited and significant drivers of SNC decisions, in each category, is presented the following section.

Structural characteristics: The structural characteristics represent the main static attributes of the supply network (e.g. the number of stages, entities and
TABLE 1

CONTRIBUTION BY AUTHOR(S)

\begin{tabular}{lc}
\hline Author & No. of published articles \\
\hline Huang G.Q. & 5 \\
Moncayo-Martínez L.A. & 3 \\
Qu T. & 3 \\
Jiao J. & 2 \\
Helo P. & 2 \\
Recio G. & 2 \\
Zhang D.Z. & 2 \\
\hline
\end{tabular}

TABLE 2

NUMBER OF PUBLICATIONS PER EACH YEAR

\begin{tabular}{|c|c|c|c|c|c|c|c|c|c|}
\hline Year & $\stackrel{\overbrace{}}{\overparen{d}}$ & $\stackrel{\infty}{\stackrel{\overbrace{}}{ٍ ~}}$ & 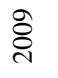 & $\stackrel{\circ}{\stackrel{ }{ }}$ & $\bar{\delta}$ & $\stackrel{m}{\stackrel{d}{d}}$ & $\frac{ \pm}{\stackrel{D}{~}}$ & $\frac{n}{\stackrel{d}{d}}$ & $\frac{0}{0}$ \\
\hline Number of publications & 5 & 2 & 1 & 1 & 2 & 4 & 1 & 1 & 3 \\
\hline \multicolumn{10}{|c|}{ TABLE 3} \\
\hline \multicolumn{7}{|c|}{ Journal titles } & \multicolumn{3}{|c|}{ Publications } \\
\hline \multicolumn{7}{|c|}{ International Journal of Production Research } & \multicolumn{3}{|c|}{6} \\
\hline \multicolumn{7}{|c|}{ International Journal of Production Economics } & \multicolumn{3}{|c|}{3} \\
\hline \multicolumn{7}{|c|}{$\begin{array}{l}\text { International Journal of Advanced Manufacturing } \\
\text { Technology }\end{array}$} & \multicolumn{3}{|c|}{2} \\
\hline \multicolumn{7}{|c|}{ European Journal of Operational Research } & \multicolumn{3}{|c|}{2} \\
\hline \multicolumn{7}{|c|}{ Computers and Operations Research } & \multicolumn{3}{|c|}{1} \\
\hline \multicolumn{5}{|c|}{$\begin{array}{l}\text { International Journal of Engineering } \\
\text { Management }\end{array}$} & \multicolumn{2}{|c|}{ Business } & \multicolumn{3}{|c|}{1} \\
\hline \multicolumn{7}{|c|}{ Journal of Manufacturing Systems } & \multicolumn{3}{|c|}{1} \\
\hline \multicolumn{7}{|c|}{ Journal of Operations Management } & \multicolumn{3}{|c|}{1} \\
\hline \multicolumn{7}{|c|}{ Management Science } & \multicolumn{3}{|c|}{1} \\
\hline \multicolumn{7}{|c|}{ Journal of Intelligent Manufacturing } & \multicolumn{3}{|c|}{1} \\
\hline \multicolumn{7}{|c|}{ Expert Systems with Applications } & \multicolumn{3}{|c|}{1} \\
\hline
\end{tabular}

product types accounted for in research) [13] [29]. Diversity of the supplier base has been considered in all of the papers we reviewed. A significant number of studies (10 out of 20) had also incorporated different market segments. Again, all of the papers reviewed had considered manufacturing processes based on tiered product assembly systems, incorporating multiple locations. All the studies had considered multi-tiered inbound processes (i.e. upstream of the SC) but only one study [14] had accounted for tiered outbound logistics processes (i.e. downstream of the SC). Furthermore, nine (out of the 20) studies had dealt with product variants in the same product family, with none of them addressing multiple product types or product platforms.

Temporal characteristics: The temporal characteristics represent the dynamics related to supply chain entities and their relationships such as variations in demand, changes in supplier base and variations in costs associated with various resources and processes. However, except for the variations in demand, other dynamic factors were hardly addressed in the literature. The type of demand, in our review, was treated under two categories: (i) static - size of the order remains the same over an extended period of time; (ii) dynamic - size of the order varying with time. There were 10 studies out of the 20 articles which dealt with dynamic demand. The relevant demand profile was explained in terms of order size, lead time and unit cost. The type of demand addressed by each study and its profile are given in Table 5. 
External influences: A range of external factors that affect the structural and temporal characteristics of SNs was identified. These include: social (e.g. changing customer requirements), economic (e.g. tax implications), geographical (e.g. natural disasters) and political factors (e.g. government regulations). None of the external factors were found to have been incorporated into the development of DS tools in the extant literature.

\section{B. Decision Parameters}

The decision parameters considered in the development of DS tools in the literature were the type of SNC decisions, SNC objectives and computational techniques. Each of these parameters is discussed below.

SNC decisions: In order to configure a $\mathrm{SN}$, it is necessary to make a number of decisions at each stage of the SC. Those SNC decisions are listed in Table 5 indicating the relevant contribution of each study towards supporting such decisions. It is evident from the entries in Table 5 that most of the studies have dealt with the selection of suppliers, the choice of transport modes and the location of facilities. Truong and Azadivar [14] have, however, also considered production policy decisions (make-to-order and make-to-stock) and the selection of facilities considering their capacities. Three other studies [15-17] have also considered the inventory level as part of SNC decisions.

SNC objectives: The SNC objectives were grouped into two categories: single objective (i.e. cost) and multiple-objective (i.e. cost and lead time) situations. The distribution of the studies against the demand type and SNC objectives while also considering the type of computational techniques used are shown in Fig. 1. Multiple-objective studies mostly use optimization techniques whereas single-objective studies adopt other techniques such as data mining and simulation. We could not find any SNC optimization studies that have addressed multiple objectives using simulation and data mining. Furthermore, Genetic Algorithms (GA) and Ant Colony Optimization (ACO) have played a leading role within the optimization category and ACO is increasingly used to deal with multiple-objective SNC problems.

Computational techniques: The complexity of solving the SNC problem increases with the number of tiers and the number of entities involved [18-19]. Hence, from a mathematical point of view, SNC has been treated as a combinatorial optimization problem [12][16]. With reference to the primary purpose of the technique in terms of addressing the SNC problem and the nature of the context in which this problem is addressed, techniques have been clustered into optimization, simulation and data mining. Mathematical modelling techniques, including evolutionary algorithms, were listed under the optimization category. Agent based modeling and discrete event simulation were placed into the simulation cluster. Rough set and decision rules were listed under the data mining category. The studies which have adopted those techniques are given in Table 4. Fig. 1 indicates that most

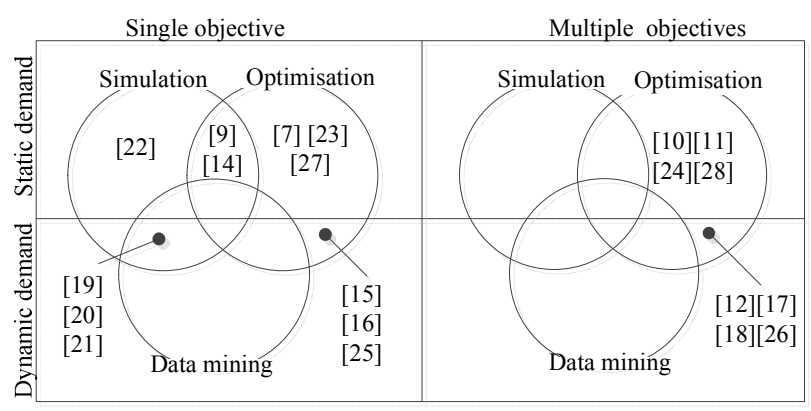

Fig. 1. Illustration of distribution of techniques against demand profile and objectives

of the studies use optimization techniques and there has been little or no attention paid to investigating the use of simulation and data mining approaches for supporting SNC decisions. Furthermore, it is evident that there have been a few attempts [19-21] at the hybridization of simulation and data mining. These studies have all used agent based modeling with both [19] and [20] using decision rules and [21] using rough set theory for configuring SNs. Akanle and Zhang [9] was the only study which had used both agent based modeling and optimization techniques to support SNC decisions.

\section{IMPLICATIONS OF ANALYSIS}

We presented the findings of our review of SNC literature under two themes (i.e. drivers of SNC decisions and decision parameters used for developing DS tools). A range of structural, temporal and environmental factors was identified as drivers of SNC decisions. The decision parameters considered in developing DS tools were SNC decisions, SNC objectives and computational techniques.

We found that a considerable number of studies have addressed the structural aspects of SNC; however, distinct characteristics of supply entities and product platforms have not been taken into account in such studies. Except for the uncertainties in demand, there has been no consideration of other factors which represent temporal characteristics of supply network entities, such as uncertain conditions in resources and processes (e.g. cycle time, cost) and changes in the supplier base. Supply network entities have also been assumed to remain the same over time (i.e. static) in most of the studies. Furthermore, none of the studies account for environmental factors in making SNC decisions.

A number of previous studies have addressed the selection of suppliers, facilities and transport options as part of SNC decisions. With regards to computational techniques used, computational time and dealing with the increasing number of variables were found to be limitations of evolutionary algorithms. Some authors have also proposed the use of data mining techniques to reduce the solution space. Additionally, it is evident that those studies with hybrid approaches have not made a notable contribution towards addressing the SNC problem as identified in this study (refer to Table 5). Instead, the studies we reviewed were found to have made unique 
TABLE 4

TECHNIQUES USED BY EACH OF THE STUDY REVIEWED

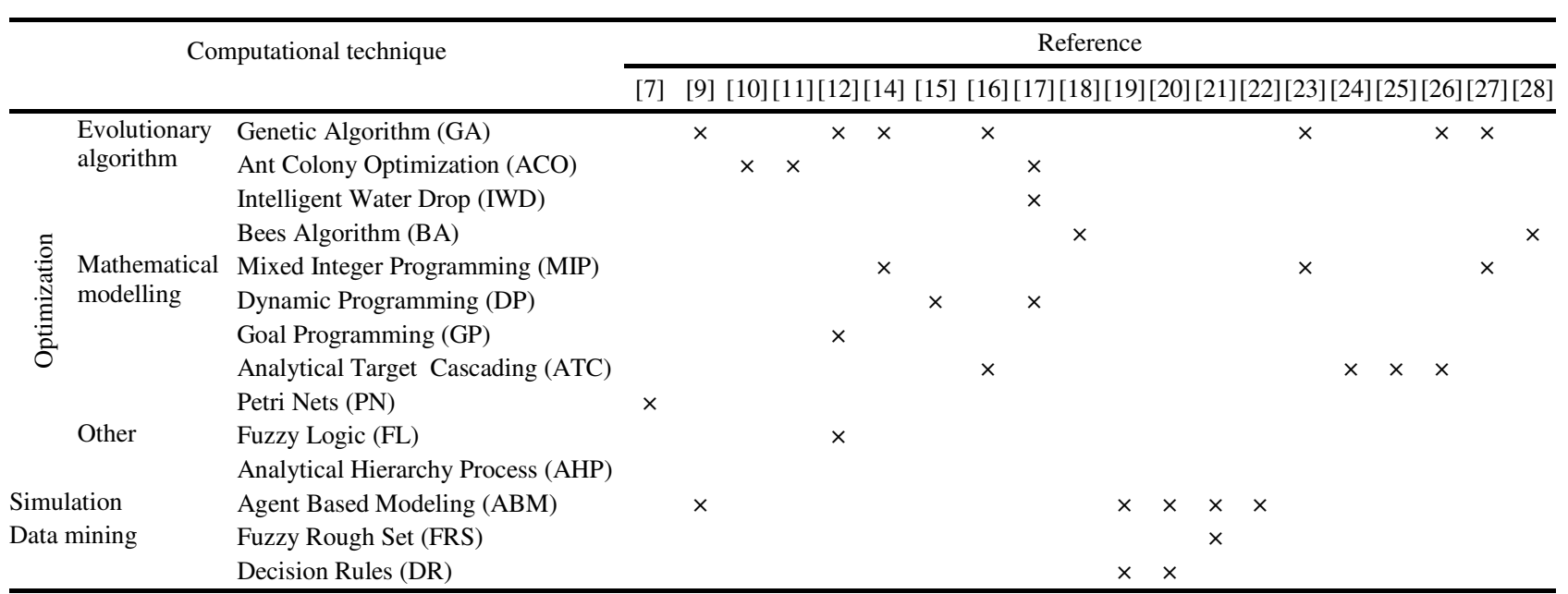

TABLE 5

SUMMARY OF THE ASPECTS COVERED BY THE LITERATURE

\begin{tabular}{|c|c|c|c|c|c|c|c|c|c|c|c|c|c|c|c|c|c|c|c|c|c|}
\hline \multirow{2}{*}{\multicolumn{2}{|c|}{ Dimensions of SNC problem }} & \multicolumn{20}{|c|}{ Reference } \\
\hline & & [7] & [9] & {$[10]$} & [11] & {$[12]$} & [14] & {$[15]$} & [16] & {$[17]$} & {$[18]$} & [19] & {$[20]$} & {$[21]$} & {$[22]$} & [23] & [24] & [25] & [26] & [27] & [28] \\
\hline \multirow[t]{2}{*}{ Type of demand } & Static & & $\times$ & $x$ & $x$ & & & $\times$ & $\times$ & & $\times$ & & & & $x$ & $x$ & & & & $x$ & \\
\hline & Dynamic & $x$ & & & & $x$ & $x$ & & & $\times$ & & $x$ & $x$ & $x$ & & & $x$ & $x$ & $x$ & & $x$ \\
\hline \multirow[t]{3}{*}{ Demand profile } & Order size & $x$ & $\times$ & $x$ & $x$ & $x$ & $x$ & $\times$ & $x$ & $x$ & $\times$ & $x$ & $x$ & $x$ & $x$ & $x$ & $x$ & $x$ & $x$ & $x$ & $x$ \\
\hline & Lead time & $x$ & $x$ & & & $x$ & & & & & & $x$ & $x$ & $x$ & & & & & & & \\
\hline & Unit Cost & $x$ & & & & $x$ & & & & & & $x$ & $x$ & & & & & & & & \\
\hline \multirow{6}{*}{$\begin{array}{l}\text { SNC } \\
\text { decision }\end{array}$} & Supplier selection & $x$ & $x$ & $\times$ & $\times$ & $x$ & $x$ & $\times$ & $x$ & $\times$ & $\times$ & $x$ & $x$ & $x$ & $x$ & $x$ & $x$ & $x$ & $x$ & $x$ & $x$ \\
\hline & Facility location & $x$ & $x$ & $x$ & $x$ & $x$ & $x$ & $\times$ & $x$ & $x$ & $x$ & $x$ & & $x$ & & $x$ & $x$ & $x$ & $x$ & $x$ & $x$ \\
\hline & Transport mode & & $x$ & $x$ & $\times$ & & $\times$ & & & $x$ & $x$ & & & & & & $x$ & $x$ & $x$ & & $x$ \\
\hline & Inventory planning & & & & & & & $x$ & $x$ & $x$ & & & & & & & & & & & \\
\hline & Capacity planning & & & & & & $x$ & & & & & & & & & & & & & & \\
\hline & Production policy & & & & & & $x$ & & & & & & & & & & & & & & \\
\hline \multirow{5}{*}{$\begin{array}{l}\text { Type of } \\
\text { objective } \\
\text { Technique }\end{array}$} & Single & $x$ & $\times$ & & & $\times$ & $\times$ & $\times$ & & & & $x$ & $\times$ & $\times$ & $x$ & $\times$ & & & & $x$ & \\
\hline & Multiple & & & $\times$ & $x$ & & & & $\times$ & $\times$ & $\times$ & & & & & & $x$ & $x$ & $x$ & & $x$ \\
\hline & Optimization & $\times$ & $\times$ & $x$ & $x$ & & $\times$ & $\times$ & $x$ & $x$ & $x$ & & & & & $\times$ & $x$ & $x$ & $x$ & $x$ & $x$ \\
\hline & Simulation & & $\times$ & & & $\times$ & & & & & & $\times$ & $\times$ & $\times$ & $\times$ & & & & & & \\
\hline & Data mining & & & & & $x$ & & & & & & $x$ & $x$ & $x$ & & & & & & & \\
\hline
\end{tabular}

contributions from other perspectives (e.g. scenario based optimization [21] and bidding mechanisms [9] which might arguably better reflect the industry practice). Overall, opportunities are still available for testing more advanced simulation and data mining techniques to deal with multiple variables and distinct objectives, using more efficient computational methods.

\section{CONCLUSION}

Supply network configuration as a research area is still in the early stages of its growth thus drawing the attention of researchers and practitioners, particularly in relation to its potential for sustaining competitiveness in dynamic business environments.

In this paper, we systematically examined the key drivers of SNC decisions and evaluated the role of DS tools and techniques used in supporting SNC decisions.
Our analysis revealed that factors related to $\mathrm{SN}$ temporal aspects and external influences were only sparsely addressed in the literature. Although structural characteristics have been addressed substantially, there is still room for incorporating factors such as product architectures and distinct characteristics of supply network entities. Research has assumed the behavior of the supply network entities to be stable (static) in all stages of the SC which we consider to be a major limitation of previous studies. With respect to the techniques used, data mining and simulation techniques are promising areas to be addressed in future research in order to reduce the computational time and enhance flexibility to deal with a larger number of variables. More importantly, developing tools for supporting decentralized decisions has been identified as a need in the context of emerging industry practices. 


\section{REFERENCES}

[1] Cognizant (n.d.), In Search of Supply Chain Excellence, Supply Chain Quarterly, Supply Chain Media LLC, MA, http://www.cognizant.com/InsightsCognizantiarticles/Cogn izanti_In-Search-of-Excellence_Supply\%20Chain.pdf. accessed on 12 February, 2013.

[2] IBM Corporation, "Connecting the Dots for Smarter Commerce: Multi-enterprise Visibility", IBM Global Services, NY, 2011.

[3] Jr. D. J. Ketchen, W. Rebarick, G. T. M. Hult and D. Meyer, "Best value supply chains: A key competitive weapon for the 21st century", Business Horizons, vol. 51 (3), pp. 235-243, 2008.

[4] PricewaterhouseCoopers LLP, "Next-generation Supply Chains: Efficient, Fast and Tailored", 2012.

[5] Supply Chain Council, www.supply-chain.org. accesses on 12 February 2013.

[6] R. H. Ballou, "Unresolved Issues in Supply Chain Network Design”, Information Systems Frontiers, vol. 3(4), pp. 417426, 2001

[7] L. Zhang, X. You, J. Jiao, and P. Helo, "Supply chain configuration with co-ordinated product, process and logistics decisions: an approach based on Petri nets," International Journal of Production Research, vol. 47, pp. 6681-6706, 20.

[8] C. Chandra and J. Grabis, "Configurable supply chain: Framework, methodology and application," International Journal of Manufacturing Technology and Management, vol. 17, pp. 5-22, 2009.

[9] O. Akanle and D. Zhang, "Agent-based model for optimising supply-chain configurations," International Journal of Production Economics, vol. 115, pp. 444-460, 2008.

[10] L. A. Moncayo-Martínez and D. Z. Zhang, "Multi-objective ant colony optimisation: A meta-heuristic approach to supply chain design," International Journal of Production Economics, vol. 131, pp. 407-420, 2011.

[11] L. A. Moncayo-Martínez and G. Recio, "Bi-criterion optimisation for configuring an assembly supply chain using Pareto ant colony meta-heuristic," Journal of Manufacturing Systems, vol. 33, pp. 188-195, 2014.

[12] B. Nepal, L. Monplaisir and O. Famuyiwa, "A multiobjective supply chain configuration model for new products," International Journal of Production Research, vol. 49, pp. 7107-7134, 2011.

[13] S. Serdarasan, "A review of supply chain complexity drivers," Computers \& Industrial Engineering, vol. 66, pp. 533-540, 2013.

[14] T. H. Truong and F. Azadivar*, "Optimal design methodologies for configuration of supply chains," International Journal of Production Research, vol. 43, pp. 2217-2236, 2005.

[15] S. C. Graves and S. P. Willems, "Optimizing the supply chain configuration for new products," Management science, vol. 51, pp. 1165-1180, 2005.

[16] G. Q. Huang, X. Zhang and L. Liang, "Towards integrated optimal configuration of platform products, manufacturing processes, and supply chains," Journal of Operations Management, vol. 23, pp. 267-290, 2005.

[17] L. A. Moncayo-Martínez, A. Ramírez-López, G. Recio, "Managing inventory levels and time to market in assembly supply chains by swarm intelligence algorithms," The International Journal of Advanced Manufacturing Technology, vol. 82, pp. 419-433, 2016.
[18] E. Mastrocinque, B. Yuce, A. Lambiase and M. S. Packianather, "A multi-objective optimization for supply chain network using the bees algorithm," International Journal of Engineering Business Management, vol. 5, 2013.

[19] S. Piramuthu, "Knowledge-based framework for automated dynamic supply chain configuration," European Journal of Operational Research, vol. 165, pp. 219-230, 2005.

[20] S. Piramuthu, "Machine learning for dynamic multi-product supply chain formation," Expert Systems with Applications, vol. 29, pp. 985-990, 2005.

[21] N. Shukla and S. Kiridena, "A fuzzy rough sets-based multi-agent analytics framework for dynamic supply chain configuration," International Journal of Production Research, pp. 1-13, 2016.

[22] F. Ameri and C. McArthur, "A multi-agent system for autonomous supply chain configuration," The International Journal of Advanced Manufacturing Technology, vol. 66, pp. 1097-1112, 2013.

[23] K. Fujita, H. Amaya and R. Akai, "Mathematical model for simultaneous design of module commonalization and supply chain configuration toward global product family," Journal of Intelligent Manufacturing, vol. 24, pp. 9911004, 2013.

[24] G. Q. Huang and T. Qu, "Extending analytical target cascading for optimal configuration of supply chains with alternative autonomous suppliers," International Journal of Production Economics, vol. 115, pp. 39-54, 2008.

[25] T. Qu, G. Q. Huang, X. Chen and H. Chen, "Extending analytical target cascading for optimal supply chain network configuration of a product family," International Journal of Computer Integrated Manufacturing, vol. 22, pp. 1012-1023, 2009.

[26] T. Qu, G. Q. Huang, V.-D. Cung and F. Mangione, "Optimal configuration of assembly supply chains using analytical target cascading," International Journal of Production Research, vol. 48, pp. 6883-6907, 2010.

[27] D. Yang, J. R. Jiao, Y. Ji, G. Du, P. Helo and A. Valente, "Joint optimization for coordinated configuration of product families and supply chains by a leader-follower Stackelberg game," European Journal of Operational Research, vol. 246, pp. 263-280, 2015.

[28] B. Yuce, E. Mastrocinque, A. Lambiase, M. S. Packianather, and D. T. Pham, "A multi-objective supply chain optimisation using enhanced Bees Algorithm with adaptive neighbourhood search and site abandonment strategy," Swarm and Evolutionary Computation, vol. 18, pp. 71-82, 2014.

[29] M. J. Meixell and V. B. Gargeya, "Global supply chain design: A literature review and critique". Transportation Research Part E: Logistics and Transportation Review, vol. 41(6), pp. 531-550, 2005.

[30] S.A. Melnyk, R.Narasimhan and H.A. DeCampos, "Supply chain design: issues, challenges, frameworks and solutions". International Journal of Production Research, vol. 52(7), pp.1887-1896, 2014.

[31] D.J. Bowersox, D.J. Closs, M.B. Cooper. Supply chain logistics management, McGraw-Hill New York, NY, 2002. 